\title{
THE USE OF LOW-VOLUME INTERESCALENE BRACHIAL PLEXUS BLOCK AND SUPRASCAPULAR NERVE BLOCK FOR SHOULDER SURGERY IN A PATIENT WITH STEINERT'S DISEASE
}

\author{
Castelo, Iker ${ }^{1}$; Martínez, Selene2; Ramírez, Carlos ${ }^{3}$ \\ 1. Anesthesia Resident of Hospital Cruces, Bilbao, Spain \\ 2. Anesthesia Staff of Hospital Santa Creu i Sant Pau, Barcelona, Spain \\ 3. Anesthesia Staff of Centro Medico Teknon, Barcelona, Spain
}

\section{BACKGROUND AND AIMS}

Myotonic dystrophy type 1 (DM1) or Steinert's disease is an autosomal dominant neuromuscular disease characterized by muscle weakness mainly of distal, axial, facial, pharyngeal and respiratory muscles. It is also accompanied by cardiac arrhythmias. The risk of general anesthesia includes cardiac rhythm disturbances, myotonic crisis and respiratory complications with increased sensibility to opioids, hypnotic and muscle relaxants; therefore, short-acting agents and regional anesthesia are frequently used. The main goal in these patients is avoid respiratory complications and prevent myotonic crisis.

\section{METHODS}

We present a 43-year-old female with DM1 who underwent elective shoulder arthroscopy. She showed muscle weakness in upper extremities and recurrent myotonia but no cardiac or respiratory symptoms.

The shoulder joint is mainly innervated by axillary, lateral pectoral and suprascapular nerves; the latter represents up to $80 \%$ of it. We performed an ultrasound-guided interescalene brachial plexus block with $5 \mathrm{ml}$ of $5 \%$ lidocaine aiming for minimal or short-timed phrenic nerve blockade. In addition we performed an ultrasound-guided selective suprascapular nerve and supraclavicular nerve blocks to provide postoperative analgesia with $15 \mathrm{ml}$ and $3 \mathrm{ml}$ of 0 ' $5 \%$ bupivacaine, respectively. We observed no hemi-diaphragmatic paresis by M-mode ultrasonography. Due to patient anxiety, we induced general anesthesia with propofol and remifentanil perfusion and a single dose of rocuronium. We monitored ASA standard parameters, temperature and neuromuscular blockade (NMB) with TOF-Cuff® monitor.

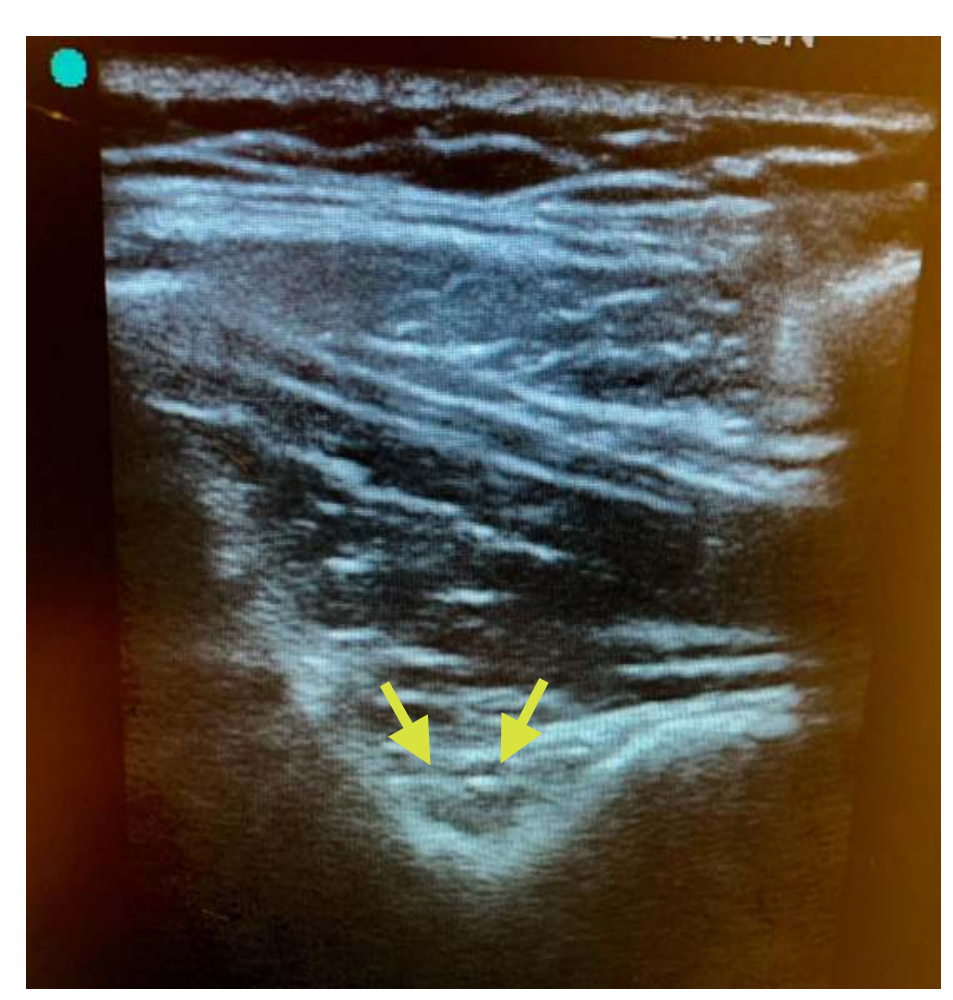

Supraescapular nerve plane block. Yellow arrows: supraescapular nerve and artery

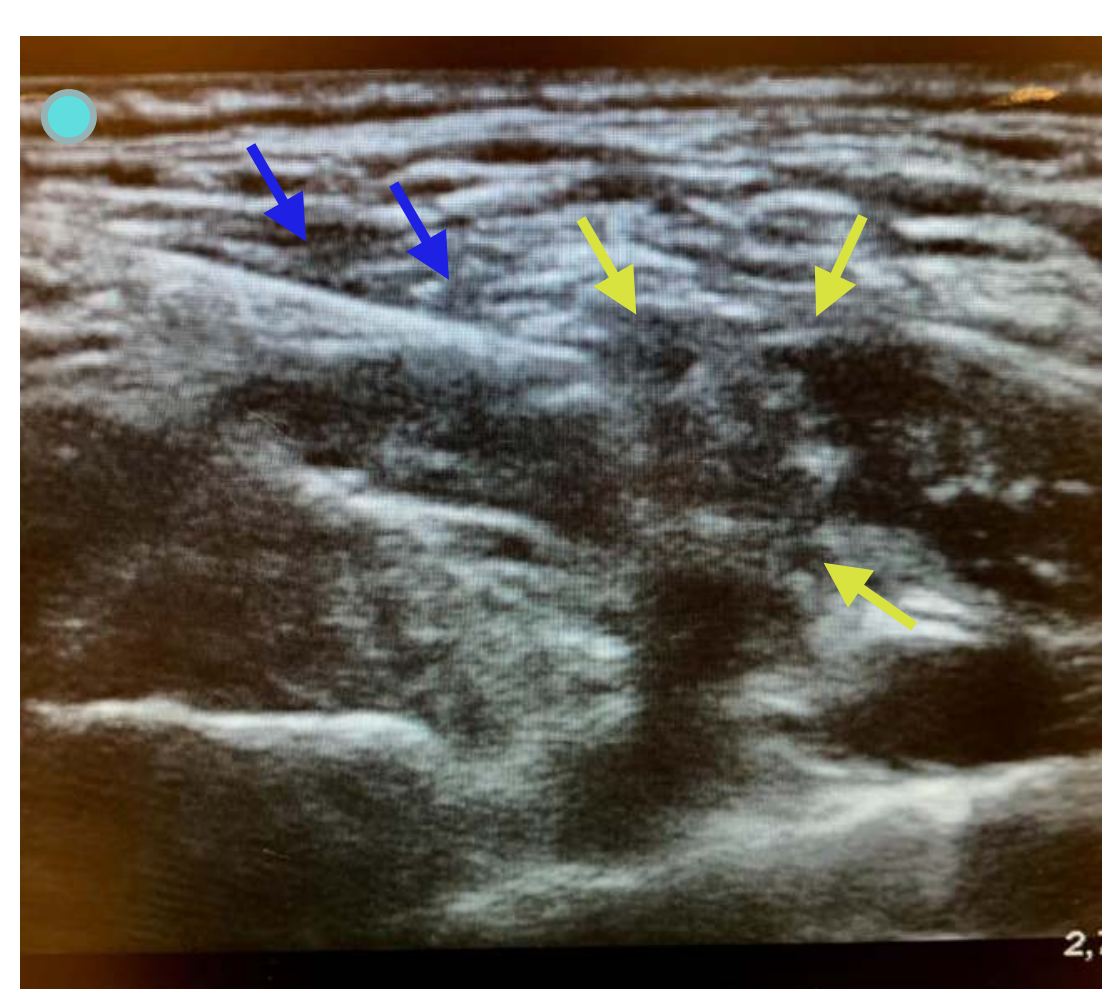

Interescalene brachial plexus plane block. Yellow arrows: brachial plexus; blue arrows: needle.

\section{RESULTS}

After surgery, NMB was reversed with sugammadex $2 \mathrm{mg} / \mathrm{kg}(\mathrm{T} 4 / \mathrm{T} 1=100 \%)$ and the patient was extubated without respiratory complications. Visual analogue scale (VSA) for pain was 0/1 immediately afterwards and 1-2/10 after 24 hours. No rescue analgesia was requested.

\section{CONCLUSIONS}

It is possible to perform interescalenic brachial plexus blocks with low-volume and high-concentration of LA for shoulder arthroscopy with good intraoperative analgesia and minimun respiratory complications in patients with DM1. 